\title{
ESPÉCIES DE TRIPSES COLETADAS EM CULTURAS DE
} FEIJOEIRO $\left({ }^{1}\right)$. C. J. Rossetto $\left({ }^{2}\right)$, L. DE Santis $\left({ }^{3}\right)$, O. Paradela Filho $\left({ }^{2}\right)$ e A. S. Pompeu $\left({ }^{2}\right)$. A ocorrência de tripses em folhas de feijoeiro no Estado de São Paulo é freqüente, e é provável que eles sejam os insetos mais constantes em plantas de feijão, nesse Estado. Desde 1963, o problema está sendo observado, e pode-se informar que, apesar disso, em geral as populações em feijoeiro são pequenas e aparentemente não causam dano de importância econômica.

Procurou-se determinar a freqüência relativa das diferentes espécies que ocorrem em feijoais.

Espécies referidas em feijâo - O quarto catálogo dos insetos que vivem nas plantas do Brasil ( $\left.{ }^{4}\right)$ relaciona as seguintes espécies, mencionadas na literatura brasileira, em feijociro: Caliothrips fasciatus (Pergande, 1895), Caliothrips ipomoeae (Moulton, 1932), Caliothrips phaseoli (Hood, 1912), Selenothrips rubrocinctus (Giard, 1901), Frankliniella californica Moulton, 1911, F. occidentalis (Pergande, 1895),Thrips tabaci Linderman, 1888.

Coletas efetuadas - Desde 1963 um dos autores (Rossetto) vem coletando uma das espécies de tripses de feijoeiro em diversas plantas, e a identificação vem sendo feita por outro autor (De Santis), com resultado discordante da literatura.

Em 1967, percorrendo campos cultivados com diferentes variedades de feijoeiro, numa área de $500 \mathrm{~m}^{2}$, em quatro localidades diferentes do Estado de São Paulo, coletaram-se insetos, ao nível das plantas, com o auxilio de uma rede de nylon presa a um arco de $30 \mathrm{~cm}$ de diâmetro.

O emprego da rede possibilitou a coleta de grande número de insetos, que permitiu uma avaliação quantitativa das diferentes espécies. As coletas não tiveram a finalidade de estabelecer comparações entre localidades, mas somente a de fazer uma amostragem quantitativa das espécies presentes.

O quadro 1 mostra que a espécie predominante foi Caliothrips braziliensis (Morgan, 1929), seguida por Sericothrips sp. O gênero Frankliniella, embora presente em todas as coletas, foi menos freqüente.

(1) Recebida para publicaçáo em 22 de novembro de 1973.

( ${ }^{2}$ Com bolsa de suplementacăo do CNPq.

(9) Professor da Faculdad de Cienclas Naturales y Museo, La Plata, Argentina.

(4) QUARTO catálogo dos insetos que vivem nas plantas do Brasll seus parasitas e predadores. Rio de Janeiro, Servico de Defesa Sanitária Vegetal, 1968. v. 2 (1.0 tomo), p.18-33. 
Quadro 1. - Número de indivíduos de diferentes espécies de tripses coletados com rede-de-mão, em feijoal

\begin{tabular}{|c|c|c|}
\hline $\begin{array}{l}\text { Local e data } \\
\text { de coleta }\end{array}$ & Espécie & $\begin{array}{l}\text { Númeto de } \\
\text { individuos }\end{array}$ \\
\hline $\begin{array}{l}\text { Itararé } \\
30 / \mathrm{XI} / 67\end{array}$ & $\begin{array}{l}\text { Caliothrips braziliensis (Morgan, 1929) } \ldots \\
\text { Sericothrips sp. } \quad \ldots \ldots \ldots \ldots \ldots \ldots \ldots \ldots\end{array}$ & $\begin{array}{l}89 \\
10\end{array}$ \\
\hline $\begin{array}{l}\text { Itapeva } \\
30 / \mathrm{XI} / 67\end{array}$ & $\begin{array}{l}\text { Caliothrips braziliensis (Morgan, 1929) } \ldots \\
\text { Frankliniella sp } \quad \ldots \ldots \ldots \ldots \ldots \ldots \ldots \ldots \ldots\end{array}$ & $\begin{array}{r}25 \\
1\end{array}$ \\
\hline $\begin{array}{l}\text { Fartura } \\
29 / \mathrm{XI} / 67\end{array}$ & 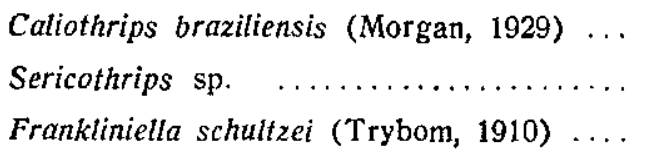 & $\begin{array}{r}300 \\
14 \\
1\end{array}$ \\
\hline $\begin{array}{l}\text { Taquarituba } \\
30 / \mathrm{XI} / 67\end{array}$ & 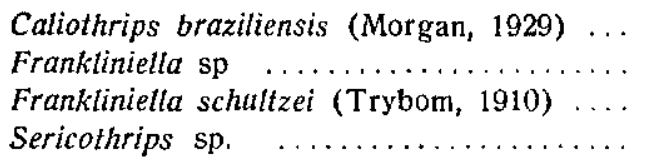 & $\begin{array}{l}2 \\
6 \\
2 \\
5\end{array}$ \\
\hline
\end{tabular}

Caliothrips ipomoeae (Moulton, 1932) é sinônimo de Caliothrips braziliensis (Morgan, 1929), devendo este último nome ser o utilizado por razão de prioridade $\left({ }^{5}\right)$. Quanto a Caliothrips fasciatus (Pergande, 1895), um dos autores (De Santis), que há mais de 30 anos recebe Thysanoptera da América do Sul, para estudo, jamais recebeu um exemplar desta espécie, o que mostra que ela ou não ocorre ou é pouco freqüuente.

Quanto a Caliothrips phaseoli (Hood, 1912), é uma espécie muito próxima a $C$. braziliensis. Faure $\left({ }^{B}\right)$, em sua revisão do gênero Caliothrips, não mencionou a América do Sul na distribuição geográfica de C. phaseoli. Presentemente $C$. braziliensis é considerada uma espécie distinta de $\mathcal{C}$. phaseoli, apesar de serem muito próximas. Segundo Faure $\left(^{\circ}\right)$, C. phaseoli tem microtrícia no terço anterior dos tergitos 111 a VII, enquanto $C$. braziliensis não tem. Se fosse aplicada com rigor essa separação de Faure, para as duas espécies, ter-se-ia que denominar $C$. phaseoli os espécimens aqui encontrados, pois todos têm algu-

( ${ }^{\circ}$ DE SANTIS, I. Tisanopteros de la provincia de La Rioja (Republica Argentina). Rev, del Museo de La Plata 8 (n.s.):39-46, 1964.

( ${ }^{*}$ FAURE, J. C. Thysanoptera of Africa-7. Entomologisk Tidskrift 83(1/2): $\triangle-49 \quad 1962$ 
mas microtricias no terço anterior dos tergitos assinalados. Entretanto, C. phaseoli típico apresentaria um número maior. Conforme mencionado por Faure $\left({ }^{6}\right)$, Kelly O'Neill distinguia C. phaseoli de C. braziliensis pela coloração das asas, que em $C$. phaseoli possui uma parte mais clara no meio da parte escura mediana, enquanto em $C$. braziliensis essa parte escura é uniforme. Faure $\left({ }^{6}\right)$ teve receio de usar esse caráter para distinguir as duas espécies, porque a figura de Hood $\left({ }^{7}\right)$, da descrıção original da espécie, pareceu-lhe não mostrar essa diferença. Os espécimens aqui coletados apresentam uma coloraçāo escura unıforme no meio da asa, somente pouco mais intensa na parte basal superior da mancha. Por tudo isso classificaram-se os exemplares brasileiros estudados como Caliothrips braziliensis.

Faure $\left({ }^{6}\right)$ sugeriu que o estudo detalhado de séries maiores de exemplares dessas duas espécies poderia revelar outras diferenças entre elas, mas é possivel também que o exame dessas séries possa revelar um gradiente nos caracteres microtricia e coloração de asa, entre as duas espécies, o que levaria a considerar essas duas espécies como sinônimas. Em tal caso dever-se-ia empregar o nome Caliothrips phaseoli, por razões de prioridade. Mas no estádio atual da taxonomia do gènero Caliothrips, os insetos desse gênero, que ocorrem em folhas de feijoeiro em São Paulo, devem ser denominados Caliothrips braziliensis (Morgan, 1929), tal como foi sugerido linhas acima. Esta espécie é polifaga e comumente encontrada em diversas plantas. A Seção de Entomologia Fitotécnica, Instituto Agronômico de Campinas, tem registrado as seguintes coletas dessa espécie: Águas da Prata SP, VII/1967, em folhas de ervilha (Pisum sativum L.); Campinas SP, VIII/67, em flores de Thumbergia lanrifolia; 1/1967, folhas de amendoinzeiro (Arachis hypogaea L.); 1/1967, folhas de feijoeiro (Phaseolus vulgaris L.); II/1968, folhas de quiabeiro (Hibiscus esculentus L.); I/1963, folhas de soja (Glycine soja S. \& Z.) ; Valinhos SP, I/1967, folhas de feijoeiro (P. vulgaris).

As espécies relacionadas no quadro 1 foram coletadas com redes de nylon em feijoal; poderiam estar apenas voando no campo ou pousadas em alguma erva daninha.

(?) HOOD, J. D. A new genus and three new species of North Amertcan

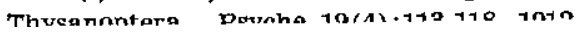




\section{Caracterizaçâo dos insetos estudados -}

\section{Caliothrips braziliensis (Morgan)}

Heliothrips braziliensis Morgan, 1929, Proc. Ent. Soc. Wash., 31:7.

Essa espécie distingue-se das demais referidas para o feijoeiro pela coloração preta do corpo, com faixas brancas transversais nas asas, aparecendo em posição de repouso, a olho nu, como um pequeno inseto preto e branco. Os indivíduos dessa espécie permanecem estacionários nas folhas, e quando molestados dão um pequeno vôo, tornando a assentar-se. Os gêneros mais próximos de Caliothrips e que poderiam ser confundidos com ele são: Heliothrips, Hercinothrips e Helionothrips, mas não estão registrados sobre feijoeiro no Brasil.

A espécie braziliensis pode ser separada facilmente de fasciatus, porque em braziliensis os pêlos da parte mediana escura da asa anterior são escuros, ao passo que em fasciatus são claros. Em braziliensis os sensórios dos artículos 3 e 4 da antena são mais compridos e finos do que em fasciatus. Além disso, são muito distintas pelas estruturas dos urotergitos III a V. As diferenças com phaseoli já foram mencionadas acima. $O$ trabalho de Faure $\left(^{\circ}\right)$ dá uma chave, mais recente que a de Moulton $\left({ }^{8}\right)$, para reconhecimento das espécies conhecidas de Caliothrips, até àquela data.

\section{Sericothrips sp.}

O gênero Sericothrips pode ser facilmente reconhecido pela presença de microtrícia nos tergitos abdominais e antena, por ter oito artículos antenais, apenas uma nervura com setas na asa anterior, pêlos mais curtos nos últimos segmentos abdominais. O gênero mais próxirno é Scirtothrips, não referido em feijoeiro no Brasil. A revisão de Bailey $\left(^{\circledR}\right)$ do gênero Scirtothrips dá uma chave para distinção dos gêneros mais próximos a Sericothrips. A espécie de Sericothrips coletada não pôde ser identificada e será estudada posteriormente por um dos autores (De Santis). E próxima de flavens, tem asas claras, corpo palha, margem anterior dos segmentos IX e X clara. As medidas mèdias, em micros, obtidas de cinco indivíduos coletados foram: compri-

(s) MOULTON, D. The Thysanoptera of South Amerlca (1). Rey. Ent. 2(4): 451-484, 1932 .

(') BALLY, S. F. A revision of the genus Scirtothrips Shull (Thysanoptera: 
mento total do corpo: 1282; comprimento da cabeça: 97; largura através dos olhos: 165; largura na parte mediana da cabeça: 162; comprimento do protórax: 122,6; largura do protórax: 195; largura do pterotórax: 274; artículos antenais, comprimento (largura): I 23 $(27,6)$; II 33(22); III 49(24); IV 55(24); V 48(18); VI 48(15); VII 11(6); VIII 13(4). Para identificação das espécies do gênero Sericothrips pode-se usar a chave de Hartwig $\left({ }^{10}\right)$, complementada por Faure $\left({ }^{11}\right)$.

\section{Frankliniella spp.}

Várias espécies de Frankliniella parecem ocorrer no feijoeiro. O gênero Frankliniella pode ser facilmente reconhecido pelas antenas de oito artículos, os dois últimos menores e afilados; insetos de cor clara ou escura; duas setas interocelares desenvolvidas, uma seta pos-ocular desenvolvida, um par de setas bem desenvolvido na margem de cada quadrante do protórax, duas nervuras com setas equidistantes em quase toda a extensão da asa anterior. Para diferenciação das espécies de Frankliniella pode-se utilizar a chave de Moulton $\left({ }^{12}\right)$, que constitui uma revisão do gênero até essa data.

Danos causados: Não existe informação quanto à importância econômica dos danos causados ao feijoeiro pelos tripses. Aparentemente esses insetos geralmente não constituem pragas, pois as populações não são grandes e as plantas não têm aparência prejudicada. O Caliothrips braziliensis pica e dilacera as células da face inferior do limbo, sugando a seiva, deixando pequenas pintas brancas no local da picada. É comum observar na face inferior das folhas de feijoeiro uma série de pequenos pontos de coloração marrom, em forma de caracol, que geralmente é atribuída a tripses. Não foi possível determinar a espécie responsável por esse sintoma. SEÇĀO DE ENTOMOLOGIA FITOTECCNICA, SEÇÃO DE MICROBIOLOGIA FITOTÉCNICA E SEÇAO DE GENÉTICA, INSTITUTO AGRONOMICO DO ESTADO DE SÃO PAULO.

(10) HARTWIG, E. $\boldsymbol{K}$. Taxonomic studies of South African Thysanoptera, including genitalia statistics and a revision of Trybom's types. Entomology Mem. Dep. Agric, Un, S. Afr. 2(11):339-499, 1952.

(11) FAURE, J. C. South African Thysanoptera-9. J. ent. Soc. S. Afr. 21(2): 354-375, 1958 .

(19) MOULTON, D. The genus Frankliniella Karny, with keys for the deter-

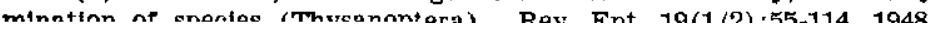




\section{SPECIES OF THYSANOPTERA COLLECTED IN BEAN CROPS}

\section{S U M M A R Y}

Collections of Thysanoptera were made in the bean (Phaseolus vulgaris L.) producing area of the State of São Paulo. Ninety percent of the specimens belonged to the species Caliothrips braziliensis (Morgan, 1929). The second most frequent species was Sericothrips sp. Two species of Frankliniella one of them identified as $F$. schultzei (Trybom, 1910) were also found.

Since 1963, Caliothrips braziliensis was the only species of Caliothrips collected by the senior author in São Paulo, not only on beans but also on other hosts.

A discussion is made on the present status of this species and about its great similarity to Caliothrips phaseoli. 